\title{
Expanding the evidence: key priorities for research on mental health interventions for refugees in high-income countries
}

\author{
M. Sijbrandij \\ Department of Clinical, Neuro- and Developmental Psychology, VU University, Amsterdam, the Netherlands
}

First published online 16 November 2017

Key words: Common mental disorders, post traumatic stress disorder, primary care, randomised controlled trials, refugees.

Current times has seen the largest numbers of forcibly displaced people ever recorded (UNHCR, 2017). By the end of 2016, approximately 65 million people had fled from their homes, among which approximately 22 million refugees, over half of whom are estimated to be under the age of 18 (UNHCR, 2017). Most of these refugees fled from Syria, South Sudan and Afghanistan. Although most externally displaced people are hosted in low and middle-income countries such as Pakistan, Ethiopia and Uganda and Iran, highincome countries have also seen an increase in refugees claiming requests for asylum. The largest number of new asylum claims over the year 2016 were registered in Germany, followed by the USA, Italy and Turkey (UNHCR, 2017).

Refugees may be present with mental health problems, such as posttraumatic stress disorder (PTSD) and depression (Fazel et al. 2005; Steel et al. 2009). Factors that contribute to the risk are the number and severity of traumatic events that happened before arriving in the country of resettlement, and postmigration living difficulties insecurity about the asylum procedure, restrictions in education or employment (Steel et al. 2009; Steel et al. 2017). Other psychiatric disorders such as psychosis are also more prevalent within refugees and migrant populations (Hollander et al. 2016).

In high-income countries such as European countries, the USA, Canada and Australia, it took until the beginning of this century for the first randomised controlled trials (RCTs) evaluating interventions for refugees to emerge (Otto et al. 2003; Hinton et al. 2004). Recently the number of RCTs has strongly increased, with five recent RCTs that appeared since 2010 (see Nose et al. (2017) for a meta-analysis).

Address for correspondence: M. Sijbrandij, Department of Clinical, Neuro- and Developmental Psychology, VU University, Van der Boechorststraat 1, Amsterdam 1081 BT, the Netherlands.

(Email: e.m.sijbrandij@vu.nl)
However, intervention studies in refugee and migrant populations are still lagging greatly behind in comparison with studies in other typical subpopulations exposed to adversities, such as people with somatic diseases (Beltman et al. 2010), or war veterans (Haagen et al. 2015).

In this issue, Giacco \& Priebe (in press) and Fazel (in press) review the evidence base for interventions for adult and child refugees, respectively. Both conclude that most of the research in refugees until now is focused on interventions for PTSD, with the strongest evidence for narrative exposure therapy (NET) to reduce symptoms of PTSD. Giacco \& Priebe (in press) suggest that pragmatic trials should also evaluate how refugees access, and benefit from, evidence-based treatments of anxiety and depression within the main mental health care system. For refugee children, the lack of studies is even more poignant. Fazel (in press) recommends that the evidence base should be expanded with RCTs on interventions for children in high-income settings (such as NET for children, named KIDNET, now mainly tested in low-income settings) and multimodal interventions that may be delivered to the larger family system, or within the school environment.

The lack of psychosocial intervention studies in refugees in high-income settings may - at least partly - be explained by the fact that research in refugee populations is particularly challenging. Within specialised refugee clinics, patients often present with comorbid disorders and disabilities (Fazel et al. 2005), instead of 'clear-cut' DSM-5 disorders of PTSD or depression. The chance that patients meet exclusion criteria such as symptoms of suicidality or psychosis may be somewhat higher than in other populations. When interventions are offered to community samples of refugees and asylum seekers, participants may be difficult to find because they may not have regular contact with primary health care providers. Patients may not be willing to engage in psychological intervention studies 
because of the stigma associated with psychological problems and lack of knowledge about the effects and scope of psychological interventions. From a research perspective, performing research in other languages than the language of the researcher is also difficult, since it requires the translation of instruments, the lack of validated cut-offs, and the involvement of native speakers for conducting the assessments. In addition, taking into account cultural concepts of distress when measuring outcomes of interventions, can be a challenge (Kohrt et al. 2014). Once included, patients may drop out, mostly due to practical reasons such as moving to another area, but also because their participation did not meet their expectations. Informing refugees and migrant patients about the pros and cons of participating in a study, therefore, require more effort than for RCTs in native populations, both in preparing a readable and comprehensible information letter, as well as orally communicating about the study procedures. Specific guidelines for performing research in refugee populations have been published recently (European Commission, 2016).

Although it is encouraging that, psychological interventions (e.g. NET and KIDNET) are effective in treating PTSD in refugees, most refugees do not access such interventions. It has been estimated that for instance in Germany, 2015 only 5\% of refugees in need of mental health care actually received treatment (BAfF, 2016). Language barriers, geographical distance to mental health care institutions, lack of knowledge about treatment options, distrust of services and stigma may prevent refugees from accessing mental health interventions. Refugee mental health care services in most high-income countries consist of lengthy treatments, delivered by scarce and expensive mental health professionals. They are mainly focused on single disorders instead of targeting more general distress, and difficulties within the larger system.

In order to scale-up interventions for common mental disorders in migrant populations, culturallyadapted and evidence-based interventions within stepped or collaborative care systems are needed. As mentioned by Giacco \& Priebe (in press), engagement of refugees with services may be facilitated by improving interpreter services. However, migrants have also reported that the use of interpreters hinders treatment (Hadziabdic et al. 2011). A way to bypass the use of interpreters is to psychosocial interventions carried out by non-specialised trained counsellors speaking the same language as the refugee. Research conducted in low and middle-income settings showed promising results with task-shifting or task-sharing strategies, in which tasks originally performed by professionals are now carried out by non-specialised counsellors or lay counsellors. Examples are the World Health Organization Problem Management Plus programme based on CBT and problem-solving techniques that have been proven effective in primary care setting in Pakistan (Rahman et al. 2016) and in a community setting in Kenya (Bryant et al. 2017), or the lay-counsellor delivered Healthy Activity Program for depression in India (Patel et al. 2017). The use of task-sharing interventions in primary care settings may also have the advantage that specialised staff members may be allocated more towards the management of severe psychiatric disorders, such as psychosis and suicidality. However, in some high-income countries, having lay counsellors carry out interventions may be restricted due to legal requirements.

It is evident that mental health services in highincome settings should be accessible, acceptable, and effective and should correspond with the needs and difficulties of refugees. Therefore, future studies may address the following key research priorities. First, the effectiveness and cost-effectiveness of scalable tasksharing interventions implemented within stepped care or community care models delivered by peerrefugees or others with a similar cultural and linguistic background need rigorous testing. In such models, mental health professionals may have the role of supervising the lay counsellors. These interventions should be multimodal, in that they target more general distress (including depression and daily living difficulties) as result of the refugee experience (see also Fazel (in press)).

Second, studies may evaluate the effectiveness of e-mental health interventions and new communication technologies, as also suggested by Giacco \& Priebe (in press). Guided internet-delivered CBT for psychiatric and somatic disorders has shown to be equally effective as a face-to-face treatment for psychiatric and somatic disorders such as depression, phobias and male sexual dysfunction (Andersson et al. 2014). Culturally sensitive e-mental health interventions targeting distress and disability should be developed and tested for refugees located in areas in which access to regular health care is problematic, such as rural areas, and for refugees with fear of stigmatization. A major challenge is to develop psychosocial interventions that do not rely heavily on literacy skills, such as mobile apps consisting of video clips.

Finally, there is also a role for hypothesis-driven fundamental research informing our knowledge about neuroendocrine and neurobiological mechanisms involved in treatment efficacy. For instance, it is yet unclear how elevated stress levels associated with ongoing stressors and insecurity influences the capacity of individuals to show inhibitory fear learning, the mechanism assumed to underlie the effect of 
exposure therapy for PTSD (Craske et al. 2008). Further, an exciting line of research is focused on epigenetic mechanisms in the intergenerational transmission of traumatic stress effects in refugees, and possibilities to interfere with such effects deserve further study (see Yehuda et al. (2016)).

Setting the research agenda for studies in refugees is now more timely than ever. With the large numbers of refugees seeking protection in high-income countries, we have the possibility to expand the evidence base of psychosocial interventions for refugees. This may not only benefit refugees that are affected by current crises but also help to prepare for future humanitarian crises.

\section{Financial support}

M. Sijbrandij has received funding from the European Union's Horizon 2020 Research and Innovation programme Societal Challenges under grant agreement No 733337.

\section{Conflict of Interest}

None.

\section{References}

Andersson G, Cuijpers P, Carlbring P, Riper H, Hedman E (2014). Guided internet-based vs. Face-to-face cognitive behavior therapy for psychiatric and somatic disorders: a systematic review and meta-analysis. World Psychiatry 13, 288-295.

BAfF (2016). Versorgungsbericht Zur psychosozialen Versorgung von Flüchtlingen und Folteropfern in Deutschland. 3. aktualisierte Auflage. Bundesweite Arbeitsgemeinschaft der Psychosozialen Zentren für Flüchtlinge und Folteropfer (BAfF): Berlin, Germany.

Beltman MW, Voshaar RC, Speckens AE (2010). Cognitivebehavioural therapy for depression in people with a somatic disease: meta-analysis of randomised controlled trials. British Journal of Psychiatry 197, 11-19.

Bryant RA, Schafer A, Dawson KS, Anjuri D, Mulili C, Ndogoni L, Koyiet P, Sijbrandij M, Ulate J, HarperShehadeh M, Hadzi-Pavlovic D, van Ommeren M (2017). Effectiveness of a brief behavioural intervention on psychological distress among women with a history of gender-based violence in urban Kenya: a randomised clinical trial. PLoS Medicine 14, e1002371.

Craske MG, Kircanski K, Zelikowsky M, Mystkowski J, Chowdhury N, Baker A (2008). Optimizing inhibitory learning during exposure therapy. Behaviour Research and Therapy 46, 5-27.

European Commission (2016). Guidance Note - Research on Refugees, Asylum Seekers \& Migrants. European Commission: Brussels.
Fazel M (in press). Psychological and psychosocial interventions for refugee children resettled in highincome countries. Epidemiology and Psychiatric Sciences. doi: 10.1017/S2045796017000695.

Fazel M, Wheeler J, Danesh J (2005). Prevalence of serious mental disorder in 7000 refugees resettled in western countries: a systematic review. Lancet 365, 1309-1314.

Giacco D, Priebe S (in press). Mental health care for adult refugees in high-income countries. Epidemiology and Psychiatric Sciences. doi: 10.1017/S2045796017000609.

Haagen JF, Smid GE, Knipscheer JW, Kleber RJ (2015). The efficacy of recommended treatments for veterans with PTSD: a metaregression analysis. Clinincal Psychology Review 40, 184-194.

Hadziabdic E, Heikkila K, Albin B, Hjelm K (2011). Problems and consequences in the use of professional interpreters: qualitative analysis of incidents from primary healthcare. Nursing Inquiry 18, 253-261.

Hinton DE, Pham T, Tran M, Safren SA, Otto MW, Pollack MH (2004). CBT for Vietnamese refugees with treatmentresistant PTSD and panic attacks: a pilot study. Journal of Traumatic Stress 17, 429-433.

Hollander AC, Dal H, Lewis G, Magnusson C, Kirkbride JB, Dalman C (2016). Refugee migration and risk of schizophrenia and other non-affective psychoses: cohort study of 1.3 million people in Sweden. British Medical Journal 352, 11030.

Kohrt BA, Rasmussen A, Kaiser BN, Haroz EE, Maharjan SM, Mutamba BB, de Jong JT, Hinton DE (2014). Cultural concepts of distress and psychiatric disorders: literature review and research recommendations for global mental health epidemiology. International Journal of Epidemiology 43, 365-406.

Nose M, Ballette F, Bighelli I, Turrini G, Purgato M, Tol W, Priebe S, Barbui C (2017). Psychosocial interventions for post-traumatic stress disorder in refugees and asylum seekers resettled in high-income countries: systematic review and meta-analysis. PLOS ONE 12, e0171030.

Otto MW, Hinton D, Korbly NB, Chea A, Ba P, Gershuny BS, Pollack MH (2003). Treatment of pharmacotherapyrefractory posttraumatic stress disorder among Cambodian refugees: a pilot study of combination treatment with cognitive-behavior therapy vs sertraline alone. Behaviour Research and Therapy 41, 1271-1276.

Patel V, Weobong B, Weiss HA, Anand A, Bhat B, Katti B, Dimidjian S, Araya R, Hollon SD, King M, Vijayakumar L, Park AL, McDaid D, Wilson T, Velleman R, Kirkwood BR, Fairburn CG (2017). The healthy activity program (HAP), a lay counsellor-delivered brief psychological treatment for severe depression, in primary care in India: a randomised controlled trial. Lancet 389, 176-185.

Rahman A, Hamdani SU, Awan NR, Bryant RA, Dawson KS, Khan MF, Azeemi MM, Akhtar P, Nazir H, Chiumento A, Sijbrandij M, Wang D, Farooq S, van Ommeren M (2016). Effect of a multicomponent behavioral intervention in adults impaired by psychological distress in a conflict-affected area of Pakistan: a randomized clinical trial. JAMA 316, 2609-2617. 
Steel JL, Dunlavy AC, Harding CE, Theorell T (2017). The psychological consequences of pre-emigration trauma and post-migration stress in refugees and immigrants from Africa. Journal of Immigration and Minority Health 19, 523-532.

Steel Z, Chey T, Silove D, Marnane C, Bryant RA, van Ommeren M (2009). Association of torture and other potentially traumatic events with mental health outcomes among populations exposed to mass conflict and displacement: a systematic review and meta-analysis. JAMA 302, 537-549.

UNHCR (2017). Global Trends. Forced Displacement in 2016. UNHCR: Geneva.

Yehuda R, Daskalakis NP, Bierer LM, Bader HN, Klengel T, Holsboer F \& Binder EB (2016). Holocaust exposure induced intergenerational effects on FKBP5 methylation. Biological Psychiatry 80, 372-380. 